\title{
Energy Potential of Canton of Tuzla (Bosnia and Herzegovina) and Possibilities of Its Rational Economic-Industrial Exploitation
}

\author{
Izet Ibreljić, Amra Nuhanović \\ University of Tuzla, Tuzla, Bosnia and Herzegovina
}

\begin{abstract}
Canton of Tuzla takes cca 2,650 $\mathrm{km}^{2}$ area of north-east Bosnia and Herzegovina. Economic structure of this geographic region, traditionally, dominates the energetic. In the last few years, this part Bosnia and Herzegovina produces near 4 million tons of coal, which is over $40 \%$ of coal producing in Bosnia and Herzegovina. Over $80 \%$ produced coal is burning away in local thermal power plants, where is producing cca 3,000 GWh electro energy. Today, Canton of Tuzla is starting the restructuration process of energetic sector towards improving its efficiency. Therefore, we expect the similar problems, as in other transition regions (e.g., closing some coal pits, ecology, reduction of labour, etc.). Also, we should take all well known fact that investing in energy capacities last over five years, and in this propriety time, here will not be any adequate thermal power plants as a relevant substitute. According to European Energy Charter, south-east Europe is forced to give up from technological outdated and economic inefficiency productive capacities, so the situation is becoming more complicated. For its welfare, it is essential to speed up all investment and reconstruction by using all available resources, as domestic, as foreign. Hence, this paper presents technical-technological and economic analysis of the energy problems in Canton of Tuzla, and of course, it's possible solving in near future.
\end{abstract}

Keywords: Canton of Tuzla, energetic, restructuration

\section{Introduction}

Energy resources have been seen more as a strategic and dynamic than as inpatient category, considering their importance in development of many regions in the world. Considering that, we have to have in mind that competitiveness today can be achieved by larger investments, higher mobility of inputs and by concentration and optimal development of extractive-energy base.

Considering some of the regions in Bosnia and Herzegovina, we can notice that there are highlighted differences about geographical schedule of energy and other resources, as well as others productive sleeps. These are mostly affected by historical circumstances, geographical and traffic position of some of the regions, available natural conditions for the use of local and regional resources, demographic characteristics, previously

Izet Ibreljić, Ph.D., Full Professor, Faculty of Economics, University of Tuzla.

Amra Nuhanović, Msc., Senior Teaching Assistant, Faculty of Economics, University of Tuzla.

Correspondence concerning this article should be addressed to Amra Nuhanović, 75.000, Tuzla, Bosnia and Herzegovina. E-mail: kozaricamra@yahoo.com. 
implemented policy decisions on the deployment of natural forces.

Canton of Tuzla is surely a most important energy region of Bosnia and Herzegovina which covers a relatively wide area, where there is important extractive capacity of coal. It is not proven that in this area, we can find reserves of oil, but there are some indications (earlier researcher of American company "AMOCO") of great prospects for future oil extraction in some parts of this Canton. A result of earlier research (Čičić \& Miođić, 1982) indicates the existence of significant geothermal potential in this area, but to verify their potentials time and significant investment in research projects is necessary. Sector for coal extraction is a very important segment of the energy structure, as in the most of the other countries in south-eastern Europe. Coal reserves in this region are often evaluated and estimated to be different because of different degrees of exploration of different bearings and applied criteria. Today, we're operating with estimated reserves which amounts about 1 billion tons. These reserves are mostly brown coal and lignite which are similar to coal extracted in other countries of south-eastern Europe. More than $80 \%$ of extracted coal is used in local thermal power plants, and smaller amounts go to the consumers or in direct export to neighbouring countries. How to use available energy potential as rational as possible is certainly one of the essential questions in Canton of Tuzla.

\section{The Energy Potential in Tuzla Canton and Preconditions for Its Use}

Coal is dominating fossil fuel at global level today, and it is nonsense to project world fuel economy perspective without assigning a prominent place to coal. The share of coal in global energy consumption is significantly reduced during time, but total volume of global demand for coal is growing continuously. Global energy balance of the fuel indicates that the energy capacity of fuel, including coal, should be extended in the future, what does not exclude closing unprofitable coal mines in accordance with current market conditions.

Coal sector in Canton of Tuzla acts as the main segment of the electricity system, as in other places. According to the statistical data 2009, Bosnia produced (Statistic Agency of B\&H, 2010) over 11,000 tons of coal, $60 \%$ of which achieved the production in Canton. Coal costs dominate the cost structure of production of the electricity in Tuzla Canton, and we can see that in Figure 1.

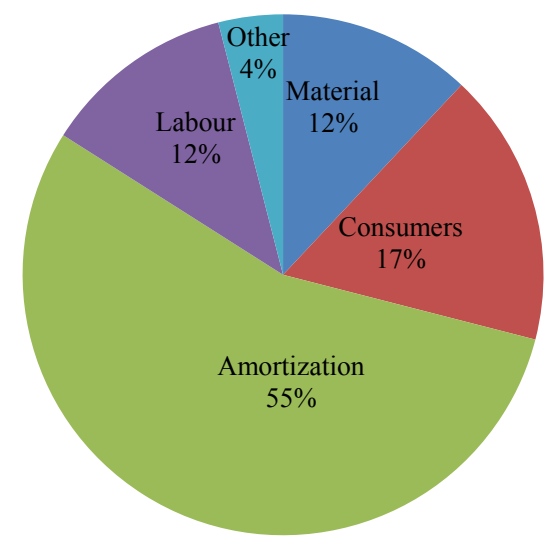

Figure 1. Cost structure in TE "Tuzla” for 2009. Source: Annual report on the activities and operations TE "Tuzla”, 2009. 
According to the same source, the cost of coal in the period 2003-2009 amounted to 59\%-76\% of the total cost in the local TE "Tuzla", while depreciation costs and labour costs amounted to cca $20 \%$ in the same period.

How to treat our own coal resources in the future? Through the prism of competitive economic production, energy independence is a key issue in many transition economies today. In Tuzla Canton, this subject was taken a flexible attitude. We should take advantage of every available resource, and at the same time, we must take care about next issues:

- Coal is now back on the economic scene, even in countries which have written off and compensate for other energy sources;

- Coal will have an important place in the global energy mix for a long time in the future and will be an important factor in social and economic development of many countries;

- A shift towards coal requires the reduction and elimination of development limits in the coal sector, first in the sphere of extraction and transport;

- More efficient use of the possibility of using clean coal is the major economic and environmental objective to be realized etc..

On the basis of the written above, a course is taken that is most rational to maximize the activation and development of economically profitable and available sources of primary energy. How long will this process lasts will depend on how domestic coal will be competitive relative to other energy sources.

\section{Basic Parameters of a Possible Investment Cycle in the Finalization of Available Energy Resources in Canton of Tuzla}

Indicators that present resources of coal in the generator of the Canton of Tuzla are encouraging and indicate the potential opportunities available to the base of coal, and also confirmed that its progress through the optimal capacity can achieve significant effects, which has special significance because it comes from domestic resources. In order to achieve maximum effect, it is necessary to protect the future opening of large open pit mines and the use of highly productive machinery, and investing in the construction. In addition, it will be necessary to update the consumption of coal and adapt to new consumer demands, to improve methods of distribution and reduce the costs of transportation and handling coal.

About the finalization of the coal, we should start from the fact that power plants were the largest consumers of coal in Bosnia and Herzegovina and that will surely continue in the future. The estimated indicators of future prices of heat in coal are relatively satisfactory. Electric power industry in Bosnia and Herzegovina has full justification to become an even bigger consumer of brown coal and lignite exclusive consumers in the future, with regard to the experiences of other countries which shows that we can organize efficient production of electric energy from mass production and cheap low fat lignite.

Within the development opportunities in the area of Tuzla Canton, there are discussions about investing in the modernization of the mine-construction of two new term blocks as follows (FMERI, 2010):

(1) Block 7 (location of TE "Tuzla") with the following characteristics

- Installed electrical power of the threshold-450 MW;

- Installed thermal power-320 MW; 
- Total investment costs (including investment in a mine)—842 million $€$;

- Beginning of the investing-2012;

- Time of the activation-2017.

(2) Block 1 (location of Banovići)

- Installed electrical power of the threshold-300 MW;

- Total investment costs (including investment in a mine)—690 million $€$;

- Beginning of the investing - 2012;

- Time of the activation-2017.

Investment operations in the future are now considered in the study prepared on the possibilities. Then will follow agreements with strategic partners, because $\mathrm{BiH}$ cannot independently financially complete this project. Implementation of the biggest post-war investment cycle in Bosnia will provide long-term large amounts of electricity for their own needs and the surplus energy to European markets.

\section{Energy Resources of the Canton of Tuzla in the Context of European Energy Connection}

Finally Bosnia and Herzegovina should ensure continuity of electricity and thermal energy production and energy efficiency by obeying commitments related to the formation of market south-eastern Europe. By signing the agreement on the establishment of the Energy Community of South East Europe, Bosnia and Herzegovina had entered a clearly defined Pan-European energy market where exists a legal and institutional framework for the free transfer and trade of electricity and natural gas.

In Europe today, there is stronger energy connecting not only with the EU but also other countries, to better ensure the supply of European consumers' electricity. It is an opportunity for southeast Europe to use their rational capacities and export surplus electricity to lacking parts of Europe. It seems that what make Bosnia and Herzegovina interesting in the European energy market are potentials of coal whose transformation would ensure that Bosnia and Herzegovina is a significant exporter of electricity. In order to achieve this, it is necessary to provide additional resources in Bosnia and neighbouring countries and to build a new system of premises electricity or cable for new technologies across the Adriatic Sea. In addition, it is necessary to put an end to investments that need now a lot of discussion. This is one of the key tasks for the Bosnia and Herzegovina civil society and its politics in the European energy process.

\section{Conclusion}

In the presented paper, the authors discuss the development of long-term energy perspective of the Tuzla Canton, the territorial unit within Bosnia and Herzegovina. Long-term forecasts in the energy sector, especially in cases where there is no strategic-development strategy, are not simple. Therefore, in this paper, we rely on the most famous international experiences as the only criterion for making the relevant courts.

The authors believe that the energy future of the Canton of Tuzla could be based on coal as primary energy sources and successive capacities. Their views are not always fully verified, empirically because it requires more research effort and a lot of real technical and economic indicators that haven't been available or 
were incomplete. For this reason, it can be a task on any of their subsequent consideration of these current issues.

\section{References}

Annual Report on the Activities and Operations TE “Tuzla”. (2009). Retrieved March 2011, from http://www.parlament.ba/sadrzaj/ostali_akti/izvjestaji/default.aspx?id=29543\&langtag=bs-ba

Statistic Agency of B\&H. (2010). Industrial production, Sarajevo, p. 51. Retrieved February 2011, from http://www.bhas.ba/tematskibilteni/ppi\%20bih_2007-2010_bos.pdf

Čičić, S., \& Miođić, N. (1982). Possible research and using geothermal potentials in Bosnia and Herzegovina. RGM, Belgrade.

FMERI. (2010). Building of electro power plants in Federation of B\&H. Sarajevo.

Kokorović, M., \& Kožarić, A. (2009). Trends in developing of energy sector in period of global economic crisis with special review on Bosnia and Herzegovina. First International Conference, Faculty of Economics, Tuzla. Retrieved March 2011, from http://internationalconference.epk.ba/admin/dokumenti/70zbornik_radova.pdf 